\title{
The Central Role of Chemistry in the Transition to the Solar Economy
}

\author{
Mario Pagliaro \\ Istituto per lo Studio dei Materiali Nanostrutturati, CNR, via U. La Malfa 153, 90146 Palermo, Italy
}

\section{ABSTRACT}

On June 8 and June 9, 2017, we gave two invited lectures at the Zelinsky Institute of Organic Chemistry (ZIOC) of the Russian Academy of Sciences, Moscow. The first lecture, "Sol-Gel Catalysts: Making Green Chemistry Possible", focused on the practical outcomes of 25 years of research on sol-gel entrapped catalysts. The second, "Chemistry for the Bioeconomy: From Discussion to Action", offered a critical insight to the forthcoming bioeconomy. Both lectures aroused much interest in the audience and ended with a vigorous discussion lasting about one

Keywords: hour. An outlook is provided herein.

Sol-gel

Solar energy

Bioeconomy

Catalysis

Nanochemistry

\section{1. «Bring organic chemistry within sol-gel glasses»}

Exactly 20 years ago I was sitting in a laboratory in Jerusalem, listening to a quick lecture of David Avnir, who turns 70 this month. David was as usual very clear: 'We've a simple programme: to bring organic chemistry from solution to the inner porosity of sol-gel glasses'. Now, there are several million organic molecules, and this may seem a far too ambitious programme. Yet, if we look at what has been achieved with solgel entrapped catalysts, we notice that a huge class of reactions can already be transferred to said inner porosity. Not only in the laboratory, but also in industry. Today, I will present you selected examples of key synthetic organic chemistry reactions that are successfully mediated by these materials, getting rid of by-products, under very mild conditions.

Let me please start from money and from we wrote in Angewandte $^{1}$ with Cristina Della Pina and Joaquim Teles, a prominent chemist at world's leading chemical company. Chemists develop new catalysts and catalytic processes which drastically reduce or even eliminate waste altogether. The fine chemical industry is driven by product, and not process, innovation. Hence, industry's managers will say yes to catalysis innovation if the new catalyst meets one out of two requirements: either it enables the development of an entirely new process with different raw materials and breakthrough economics; or the new catalyst, offering a moderate to good economic improvement, can be developed as a drop-in for existing plant and process.

This is exactly what ORMOSIL-entrapped catalysts do: they often provide breakthrough economic improvement, and they can easily be used as drop-in solutions. And this is the reason why they were commercialized.

Their features and benefits are well established: ${ }^{2}$ the ceramic nature ensures unprecedented chemical and physical stability; the huge surface area and accessible inner micro- or mesoporosity allows high dispersion of the catalytic species and excellent applicability to flow chemistry, whereas the sol-gel process carried out in liquid phase enables true reproducibility in the production of materials of high and accurate catalyst loading.

Finally, the sol-gel encapsulation phenomenon so well described by Avnir in a now classical 1995 paper $^{3}$ explains both their high air and moisture stability and exceptional catalytic activity: sol-gel materials, indeed, are true chemical sponges.

\section{Representative entrapped catalysts}

Listing even a fraction of all sol-gel entrapped materials doing catalysis would require three or four lectures. Hence, I will give you just one or two examples describing the performance of ORMOSIL-entrapped metal nanoparticles, ion pairs, photocatalytic oxides, organocatalyst and metal complexes.

\subsection{Nanoparticle@ORMOSIL}

The first example is the broad scope and selectivity of SiliaCat $\mathrm{Pt}(0)$, an ORMOSIL matrix encapsulating $\mathrm{Pt}$ nanoparticles prepared using an innovative alcohol-free sol-gel route, ${ }^{4}$ in mediating the hydrogenation of different nitro compounds. ${ }^{5}$

The material selectively affords complete or very high yields of functionalized anilines under hydrogen balloon, at room temperature in methanol in small amount. In comparison to other commercial platinum catalysts SiliaCat $\operatorname{Pt}(0)$ is much more reactive, with complete conversion after $0.5 \mathrm{~h}$ with just $0.5 \mathrm{~mol} \%$ catalytic amount. Furthermore, selectivity is significantly higher, with $4 \%$ aniline formed as unique by-product. Leaching of Pt and $\mathrm{Si}$ is minimal, whereas the catalyst reused in several consecutive cycles affords complete substrate conversion with $99 \%$ selectivity even in the $7^{\text {th }}$ cycle. 
The very same catalyst can be successfully employed, again in modest amount $(0.5-1 \mathrm{~mol} \%)$, to selectively mediate the hydrosilylation of different olefins at room temperature or at 65 ${ }^{\circ} \mathrm{C}$, depending on the substrate. ${ }^{6}$ This closes the organosilicon synthetic cycle, because the SiliaCat catalyst itself is made out of an alkyl-trialkoxysilane in its turn obtained via olefin hydrosilation. What is also relevant from a practical viewpoint is that the process scaled up 50 times retains both the high selectivity and conversion degree observed on the $2 \mathrm{mmol}$ scale.

Similar excellent results are obtained with SiliaCat $\operatorname{Pd}(0)$ enabling the selective hydrogenation of nitro compounds in the presence of different functionalities including carboxylic acid, ester, amide, and halide groups under $1 \mathrm{~atm}$ hydrogen at room temperature in batch. ${ }^{7}$ Showing evidence of the potential of these materials in flow chemistry, however, the hydrogenation using ammonium formate under flow affords full selective conversion in $14 \mathrm{~min}$ only, versus $60 \mathrm{~min}$ required for maximum $95 \%$ selectivity under batch conditions. ${ }^{8}$

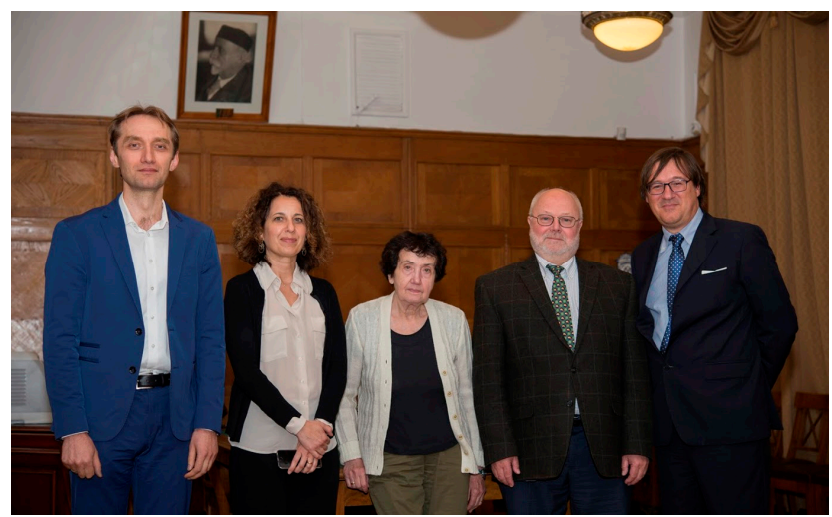

Figure 1. From left to right: Valentine P. Ananikov, Rosaria Ciriminna, Irina. P. Beleteskaya, Mikhail P. Egorov, Mario Pagliaro in Moscow, Zelinsky Institute of Organic Chemistry, Russian Academy of the Sciences, June 8, 2017.

Another example, very important from the viewpoint of public health, is that SiliaCat $\operatorname{Pd}(0)$ is a chemoselective and highly efficient catalyst for the hydrogenation of a wide variety of vegetable oils in a simple hydrogen balloon at room temperature promoting at ultralow $0.1 \mathrm{~mol} \%$ load the full hydrogenation of vegetable oils with no cis/trans isomerization and with negligible leaching of valued $\mathrm{Pd} .^{9}$

It is well known that in the hydrogenation of vegetable oils with Ni-based catalysts some unsaturated bonds are unselectively converted to trans position. What is perhaps less known is that metabolic and epidemiological studies provide strong evidence that trans fatty acid intake significantly increases the risk of coronary disease, sudden death from cardiac causes, and diabetes.

It is also remarkable here that Russia's scientists have investigated the use of palladium catalysts for margarine production since the early 1960s up to Murzin and co-workers who reported in 2008 successful results using a over a Pd carbon nanocomposite catalyst at margarine plants in Zaporogskiy, Lvov and Kazan in industrial conditions in the selective hydrogenation of sunflower oil. ${ }^{10}$

A suitable drop-in solution might be the replacement of commercial catalysts currently used for the production of squalane via squalene hydrogenation, with the newly developed spherical SiliaCat $\operatorname{Pd}(0) .{ }^{11}$ The new catalyst indeed outperforms several commercial catalysts in the solvent-free fully chemoselective hydrogenation of squalene, both of vegetable or animal origin.

Getting to gold catalysis, the issue is very simple. For gold catalysis to become ubiquitous in the fine chemical and pharmaceutical industry as palladium catalysis has become today, recyclable catalysts using an ultra-low amount of gold will have to be developed. In year 2000, indeed, gold was priced less than $\$ 300 /$ oz. In October 2014 , the price had risen to $\$ 1246 /$ oz when, for comparison, $\mathrm{Pd}$ was priced at $\$ 775 / \mathrm{oz}$.

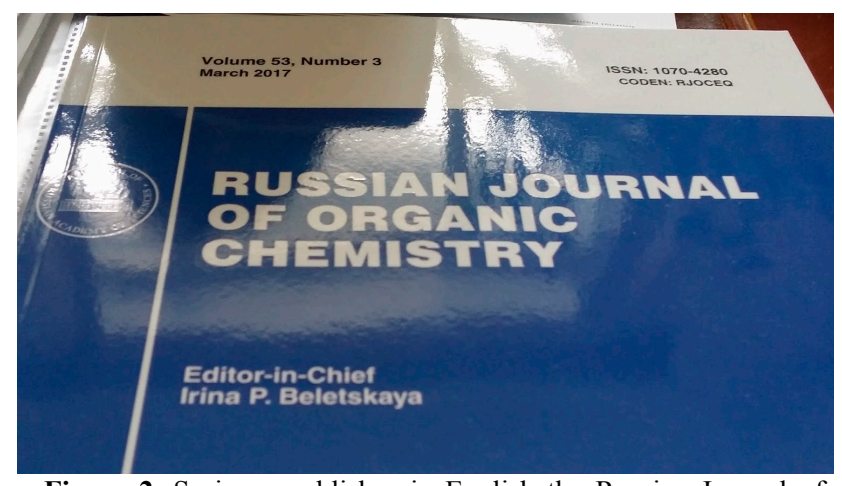

Figure 2. Springer publishes in English the Russian Journal of Organic Chemistry, edited by Irina P. Beletskaya.

One such catalyst could be the SiliaCat $\mathrm{Au}(0)$. The catalyst successfully mediates the selective oxidation of alcohols either under solvent-free conditions with oxygen ${ }^{12}$ or with hydrogen peroxide in biphasic system. ${ }^{13}$ Remarkably, ending the 2015 $\operatorname{article}^{13}$ we were anticipating forthcoming application of this new material to different applicative domains of chemistry, including environmental remediation.

It took Israeli colleagues a few more months to report highly successful application of this new class of materials to the dehalogenation of brominated disinfection byproducts typically produced during water disinfection with chlorine, owing to trace amounts of bromide. ${ }^{14}$ The catalyst successfully catalyzes the debromination of all brominated products affording complete conversion into valued succinic or acetic acid. Above all, the catalyst is stable and reusable. It is interesting to review what Albo and the other Israeli colleagues write in the forthcoming September 2017 issue of Chimica Oggi - Chemistry Today we had the privilege to edit:

«The applicability of a new technology is highly dependent on the cost effectiveness of the suggested process. This is even more relevant regarding environmental technologies due to relatively low market values characteristic to this field. The ability to obtain reproducible catalysts by using sol-gel technology, the low catalytic amount of gold used in the preparation of the matrices and the stability of the catalyst are important advancements towards the implementation of highly active noble metal nanoparticles in water remediation processes»». ${ }^{15}$

\subsection{Organocatalyst@ORMOSIL}

The selective oxidation of alcohols to carbonyls is a key process in the production of fine chemicals that for decades has been carried out in industry using highly toxic, hazardous and potentially highly polluting $\mathrm{Cr}(\mathrm{VI})$. Today, however, alcohol selective oxidation in industry is mostly performed catalytically, and very often using nitroxyl radical TEMPO, a stable radical species first synthesized in Russia by Lebedev and Kazarnowskii in $1959 .{ }^{16}$ Oxidation either uses $\mathrm{NaOCl}$ with potassium bromide as primary oxidant or aerobically with a copper(I) co-catalyst. ${ }^{17}$ 
SiliaCat TEMPO was one of the first sol-gel catalyst reaching the marketplace after Reetz's sol-gel entrapped lipases ten years before. The solid catalyst can be successfully used for the oxidation of a wide variety of alcohols under batch or flow conditions. ${ }^{18}$ However, whereas under batch it takes $1 \mathrm{~h}$ to achieve maximum $97 \%$ benzyl alcohol conversion, at $0{ }^{\circ} \mathrm{C}$ and with $\mathrm{KBr}$ as co-catalyst, under flow it takes $0.3 \mathrm{~min}$ to get full alcohol conversion to pure benzaldehyde ( $100 \%$ selectivity) but this time at room temperature and without $\mathrm{KBr} .{ }^{19}$ For comparison, the same oxidative reaction over resin-immobilized TEMPO under flow still requires cooling at $0{ }^{\circ} \mathrm{C}$ and the use of $\mathrm{KBr}$ for optimal yield and selectivity.

\subsection{Ion pair@ORMOSIL}

Another example is ORMOSIL-entrapped TPAP. The ion pair tetra- $n$-propylammonium perruthenate (TPAP) encapsulated in silica employed in the aerobic oxidation of alcohols is modestly active, but the activity rapidly increases with the amount of methyl groups in the ORMOSIL matrix; with the fully methylated ORMOSIL showing activity comparable to that of homogeneous TPAP. ${ }^{20}$ Furthermore, along with Sandro Campestrini and Massimo Carraro from Padua University, we reported its excellent selective activity in alcohol oxidation with $\mathrm{H}_{2} \mathrm{O}_{2}$ in solution added dropwise. ${ }^{21}$

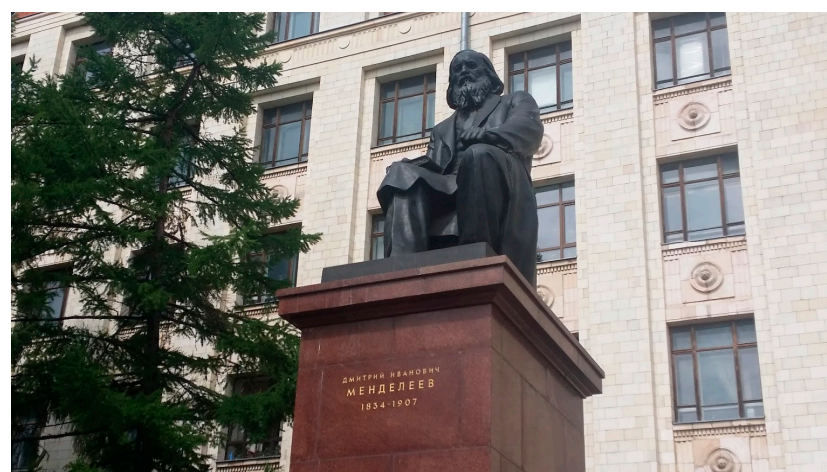

Figure 3. Statue od Dmitry Mendeleev at the entrance of the Chemistry Department, Lomonosov Moscow State University.

FluoRuGel, namely TPAP encapsulated in a fluorinated silica matrix shows similar good activity and a unique kinetics in alcohol oxidative dehydrogenation in supercritical $\mathrm{CO}_{2}{ }^{22}$ Contrary to TPAP in solution, where it progressively loses activity due to aggregation of the intermediate ruthenate species, the FluoRuGel catalyst is smoothly recyclable as the sol-gel encapsulation of perruthenate in the inner porosity of the organosilica matrix entirely prevents aggregation.

\subsection{Metalcomplex@ORMOSIL}

The example of an encapsulated metal complex is SiliaCat DPP-Pd, namely the ORMOSIL-entrapped Pd(II) complex synthesized from a diphenylphosphine-functionalized silane and methyltrethoxysilane. In general, the catalyst shows excellent selective acivity in a wide variety of $\mathrm{C}-\mathrm{C}$ cross-coupling reactions. $^{23}$

For example, it can streamline the Valsartan synthesis scaling up and making heterogeneous a key Suzuki-Miyaura coupling reaction step to afford $100 \%$ yield in coupled product in $1 \mathrm{~h}^{24}$ The catalyst in the batch reaction is not recyclable though being practically leach-proof, while under flow it enables the much faster synthesis of another sartan, Telmisartan, in which the residence time in the last reaction step over SiliaCat DPP-Pd is less than 5 min. $^{25}$
A comparative study of the most common immobilized diarylphosphine- and triarylphosphine-based palladium catalysts used in $\mathrm{C}-\mathrm{C}$ coupling reactions in the $\mathrm{X}$-Cube flow reactor ${ }^{26}$ shows that SiliaCat DPP-Pd has far superior leaching resistance and stability with respect to the other three catalysts, with very low levels of leached Pd (332 $\mu \mathrm{g}$ for the Heck and $39 \mu \mathrm{g}$ for the Suzuki reaction), even though use led to formation of Pd black.

As put by Alcázar and co-workers who employed SiliaCat DPP-Pd in a variety of cross-coupling reaction under flow with remarkable performance stability on stream, the catalyst «costs less than other commonly used palladium sources, such as palladium acetate or Pearlman's catalyst, does not require catalyst separation from the product, drastically reducing solvent utilization, while providing increased yields of valued crosscoupled products at a much faster rate than any homogeneously catalyzed process in a batch reactor».$^{27}$

The catalysis is truly heterogeneous, even though a contribute from "cocktail" catalysis ${ }^{28}$ revealed by Ananikov's team is most likely involved, with SiliaCat $\operatorname{Pd}(0)$ showing minimal leaching values in a wide variety of cross-coupling reactions with widely different substrates. ${ }^{29}$ Getting therefore back to the premise of this lecture, this a technology that managers would consider for scale-up and practical utilization because these outcomes directly translate into reduced cost due to yield improvement, lack of product contamination, reduced solvent utilization and waste disposal cost, and quicker product delivery to customer.

\subsection{Metaloxide@ORMOSIL}

The last example is the sol-gel entrapped photocatalyst called SiliaSun embedding a short-gap semiconductor in a $10 \%$ methylmodified silica matrix. Both amorphous silica and organosilica are transparent glasses, a feature which generally makes possible visible-light photocatalysis through the inner porosity of these materials. In the case of nanostructured bismuth tungstate, its encapsulation greatly contributes to the improved separation of photogenerated electron-hole pairs under visible light irradiation, as shown by the much lower photoluminiscence intensity profile of SiliaSun compared to that of non-entrapped tungstate. ${ }^{30}$

Along with Professor Yi-Jun Xu at Fuzhou University we showed improved catalytic activity in the aerobic selective photooxidation of glycerol to dihydroxyacetone under visible light. ${ }^{30}$ Similarly, the sunlight-driven photo-oxidation of trans-ferulic and trans-cinnamic acid dissolved in water with air as primary oxidant over SiliaSun affords unprecedented yields of valuable products such as vanillin, benzaldehyde, benzoic and vanillic acid, whereas well known photocatalytic $\mathrm{TiO}_{2}$ is poorly active. ${ }^{31}$

\section{The inevitable solar economy}

The second lecture ("Chemistry for the Bioeconomy: From Discussion to Action") offered a critical overview of the bioeconomy starting from the oil, wealth and population conundrum. Recently along with Professor Meneguzzo, we have identified the relationship between wealth and population, and that between wealth and total energy consumption. ${ }^{32}$ If global population will keep growing along the current trajectory, in 2025 about 800 million people will add to current population, requiring more than 11 million additional barrels per day over current oil production levels.

We simply do not know where to take all this oil from. Hence, the solar economy is the only option we have to avoid unpleasant consequences. In brief, sunlight, water and wind will replace fossil fuels to generate electricity that will be used for all energy end uses, and biomass will replace petroleum as raw material of 
4

the chemical industry. I do not have time to treat the biorefinery topic, and recommend to read the excellent quantitative insight on the second generation biorefinery of Professor Percival Zhang, ${ }^{33}$ who lately attended the SuNEC conference in Sicily. Whatever, in the transition to the bioeconomy, chemistry will play a central role.

\subsection{First pillar, solar energy}

Let me start from solar energy. As put it by Peter Varadi, a pioneer in solar energy, very few people realize that without the invention of solar power many things we are using today such as cell phones, TV, internet, global weather service, the Glonass and Gps systems, and manned space stations would not be possible. Almost two centuries ago, Dmitry Mendeleev said to the Czar that burning oil to make energy was «akin to firing up banknotes in the kitchen stove». ${ }^{34}$ Yet, for more than a century hydroelectric and nuclear power have been the only two alternatives available.

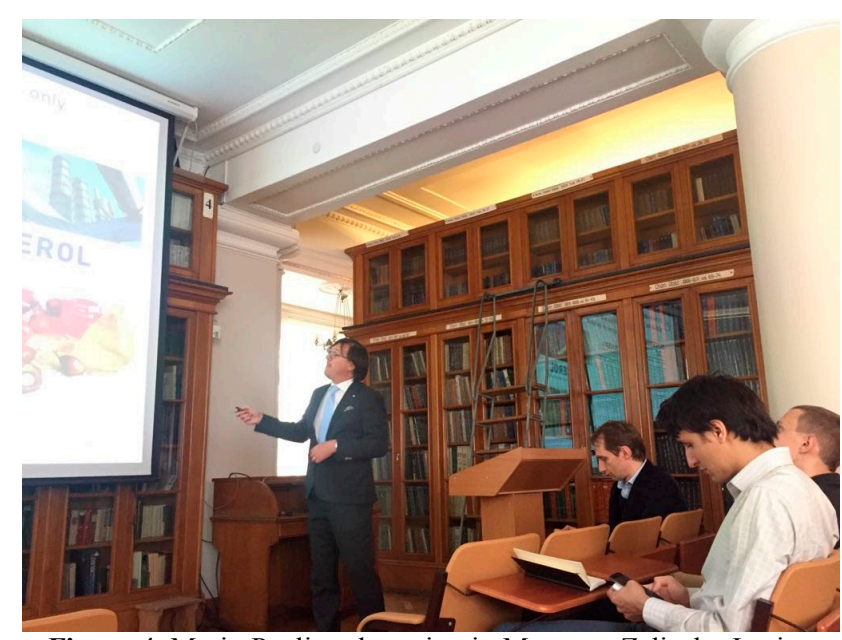

Figure 4. Mario Pagliaro lecturing in Moscow, Zelinsky Institute of Organic Chemistry, Russian Academy of the Sciences, June 9, 2017.

All has changed in the last twenty years, with an unexpected boom in renewable energy, especially wind and solar power, ${ }^{35}$ that will shortly change the global energy scenario. For example, in India a few weeks ago solar electricity was priced at 3.7 $\$$ cents $/ \mathrm{kWh},{ }^{36}$ which is lower than the current wholesale coal power price of 4 cents per $\mathrm{kWh}$. In detail, the owners of a 500 MW solar park agreed to build the plant in 12 months and sell the electricity to the Government at this flat tariff for 25 years. This shows not only how cheap, but also how reliable is this technology. India now knows it very well, and the Government just cancelled orders for huge coal fired power plants: $14 \mathrm{GW}$, equivalent to 14 nuclear power stations. ${ }^{37}$

Let me show also how renewable energy ends the conventional electricity business. Italy, a small country in terms of geography but a large one from the industrial viewpoint, currently hosts $20 \mathrm{GW}$ of installed solar photovoltaic power. The country in 2016 demanded 310 billion of kWh, out of which 106 $\mathrm{kWh}$ came from renewable energy sources. Correspondingly, the wholesale price of electricity went down from 7.48 cents per $\mathrm{kWh}$ as of 2007 to 4.28 cents in 2016. A similar trend is observed in cloudy Germany where the installed solar park exceeds $40 \mathrm{GW}$ and where negative electricity prices on the marketplace on weekends or holidays have become very common, with the wholesale price of electricity having decreased to historic low, 2.88 cents $/ \mathrm{kWh}$, in 2016 . $^{38}$
And this is just the beginning of the solar economy. Hence, utilities in these countries only have two business options: start selling electricity to the owners of electric vehicles, and installing "PV + storage systems" to their customer premises.

Storage of electricity means Li-ion batteries, which also means electric mobility. Again, just one example: 2013 in China saw the sale of 1,672 electric buses. In 2016 the figure increased to 116,000 , namely almost two orders of magnitude growth in less than three years. The city of Shenzhen is planning to an all electric fleet of 15,000 buses by the end of 2017. This year!

Developed by chemists, including the founder of China's and world's largest Li-ion battery maker, ${ }^{39}$ the Li-ion energy storage (and release) technology works, being reliable, scalable and increasingly affordable thanks to a steep learning curve.

Last year I gave a lecture on solar energy to young Russian managers training in Sicily. I told them how the head of Rusnano, a Russia's government company charged to support business in nanotechnology, asked a Russian scientist supporting the start of solar panel manufacturing to come back when the price of solar electricity would become lower than that of nuclear electricity. That moment has long come, and now Russia has an excellent maker of solar PV modules financed exactly by Rusnano. ${ }^{40}$

\subsection{Second pillar, bioproducts from biomass}

The global nature of the environmental and energy crises requires us to accelerate international collaboration for the transition to a true bioeconomy based on renewable energy and renewable raw materials, and in particular from agriculture, forestry, food and fish processing biomass waste.

May I give you just a few examples of value added bioproducts obtainable from agriculture or fishing waste for which we need new green chemistry processes. The first one is pectin, the most valued natural hydrocolloid, industrially obtained from citrus peel and to a lower extent from apple pomace. Traditionally employed as gelling agent, pectin has nowadays tens of applications as emulsifying and stabilizing agent, as well as active ingredient in numerous cosmetic and nutraceutical products. ${ }^{41}$ The $\$ 1.6$ billion world market is growing quickly, and the price over the past five years has doubled.

The industrial extraction process is based on hydrolysis with diluted hot mineral acids, followed by precipitation with organic solvent. In 1991, following new environmental regulation, US pectin producers exported all pectin plants to Mexico, whereas in Soviet times a number of facilities were producing pectin (from apple and sugar beet). All plants were subsequently closed and now Russia imports $\$ 90$ million worth of pectin each month, though a new 1,000 tonnes/year pectin plant is being erected in the Belgorod Region.

A similar trend is observed for citrus essential oils: booming demand, insufficient supply and ever higher prices. Along with Professors Cravotto in Italy and Ilharco in Portugal, we have developed an eco-friendly, solvent-free microwave extraction process which enables the concomitant isolation of pectin and essential oils (EOs) from waste citrus peel, ${ }^{42}$ as well as from different citrus fruit parts. Not only very high yields of pectin and essential oils are obtained, but we also discovered that using different fruit parts -- outer skin, peel, and waste -- as sources for pectin and EO affords different bioproducts. For example, EOs extracted from the exocarp contain higher amounts of oxygenated 
monoterpenes, whereas those extracted from the exo-/mesocarp are richer in flavone and furanocoumarin derivatives. ${ }^{43}$

Another example are olive biophenols: powerful bioactive compounds exerting multiple health benefits. ${ }^{44}$ Tens of nutraceutical and cosmetic products using olive biophenols as active ingredients are already available on the marketplace. These natural phenolics are suitable for large-scale replacement of synthetic phenols, sulfites and other synthetic antioxidants and antimicrobials in foodstuffs and beverages, transforming an health issue into an opportunity for health improvement. ${ }^{45}$ For example, Spanish researchers two years ago showed that frying vegetables in olive oil increases the amount of phenolic compounds in fried vegetables. ${ }^{46}$ Hence, the opportunity to replace toxic TBHQ (tert-butyl hydroquinone) in hydrogenated canola oil used to fry chips with olive biophenol extracts.

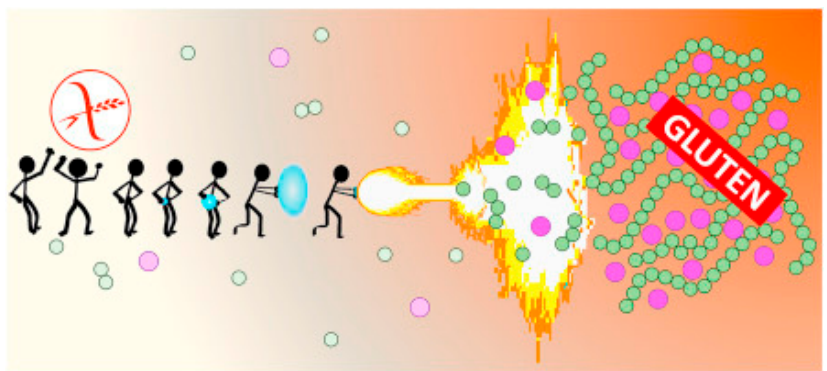

Figure 5. Beer obtained via the new controlled hydrocavitation process developed by Italy's Research Council is practically glutenfree.

Sicily grows olive orchards since more than 2,500 years, and still the production of olive mill waste water continues to be a serious environmental problem, with several oil mills being forced to close every year due to water and soil pollution. In 2016 our Lab helped a company to adapt the biophenol integral extraction protocol developed by Roberto Crea in the early 2000 s for the three-phase olive mill, to a large two-phase mill operating in Sicily. ${ }^{47}$ The new set-up allowed extensive recovery of olive phenolics, transforming previous waste into a biophenol extract of unprecedented quality and in a source of revenues for the milling company, while eliminating a source of potential pollution altogether. Italy's Labor Minister and the vice Minister of Science visited the plant last November congratulating Italy's Research Council for supporting the new bioeconomy initiative.

The third example are supplements containing long-chain omega-3 fatty acids, namely a $\$ 3.3$ billion market growing at fast pace due to multiple beneficial health effects associated to omega-3 docosahexaenoic (DHA) and eicosapentaenoic (EPA) fatty acids.

Industry traditionally extracts omega-3 from fish oil using processes that are energy intensive and use organic solvents. For example, Russia has a huge fishery equipped with state-of-the-art vessels, and a huge fish processing industry. The country recommends the world's highest daily intake of omega-3 EPA and DHA: 1,300 mg, while most countries recommend $250 \mathrm{mg}$. Three years ago, a student at the Arctic University of Norway, analyzed the composition of 13 marine omega-3 supplements on Russian and Norwegian markets. The results confirmed that «an increase in reliability of producers...is essential...». ${ }^{48}$

In Sicily, an island with a large fishing fleet, we do not even extract these valued molecules: we throw them away into the sewage in their triglyceride form, and at times they invade the roads as happened in a fisherman village near Palermo last year. Clearly, we need green alternatives to expand and improve the production of omega-3 extracts, ${ }^{49}$ especially with the aim to obtain these essential polyunsaturated fatty acids from fish processing waste available in $>20$ million tonnes/year amount, maximizing of benefits for all involved. For comparison, the global omega-3 fatty acids market volume in 2017 will be 160,000 tonnes. ${ }^{50}$

The last example of innovation in green chemistry applied to the bioeconomy is the application of a technology that has been widely progressed in Russia and in India: hydrodynamic cavitation. We joined Professor Meneguzzo and Dr Albanese in Florence to develop an entirely new beer-brewing process using a simple Venturi tube that produces cavitation within the wort. ${ }^{51}$

Forming microbubbles whose rapid collapse locally creates temperatures and pressures that may exceed $1,000 \mathrm{~K}$ and 5,000 bar, cavitation pulverizes malted barley within a few minutes thereby avoiding the necessity for it to be dry milled. Furthermore, hydrodynamic cavitation increases the rate at which starch passes from the pulverized malted barley into the wort, so that washing of the malt to remove trapped starch also becomes unnecessary. The transformation of starch into simpler sugars now takes place at lower temperatures. No boiling is needed and the activation temperature of enzymes drops by about $35^{\circ} \mathrm{C}$, shortening the time needed for saccharification, while causing unpleasant volatile gases to degas quickly.

Finally, the beer obtained with this new process is practically gluten-free, which is another extremely important finding as the number of gluten-intolerant and caeliac patients across the world has reached unprecedented levels. ${ }^{52}$

\section{Fostering cooperation}

The lectures were part of an intense scientific programme. Following a visit to the world-renown Laboratory of Professor Valentine Ananikov, on June 8th, the Italian scholars met with Dr. Denis Chusov, Prof. Sergey Osipov, Prof. Alexander Trofinov and Prof. Natalia Belkova at the Nesmeyanov Institute of Organoelement Compounds. In the afternoon, they met with Dr. Alexey Sukhorukov, Dr. Anatoly Vereshchagin and Dr Elena Shubina. The scientists offered an extremely interesting overview of their recent work.

On June 9th, they met with Professor Irina P. Beletskaya at Lomonosov Moscow State University discussing possible avenues of cooperation. Editor-in-chief of The Russian Journal of Organic Chemistry, Russia's academician and organic chemistry giant, Professor Beletskaya offered also an inspirational overview of contemporary organic chemistry.

After a visit to the unique building and surroundings of Lomonosov University, in the early afternoon, we were presented theit research outcomes by $\mathrm{PhD}$ candidate and post-graduate students Dmitry Eremin, Kirill Erokhin, Alexey Galushko, Evgeniya Borkovskaya, Evgeniya Degtyareva and Sergey Yakukhnov.

Founded in Saint Petersburg by the Czar Peter the Great in 1774, the Russian Academy of Sciences is the leading scientific institution of the world's largest country advancing basic and applied knowledge in all fields of the sciences. After the Soviet period during which it incorporated the name of the USSR (19251991), it was reconstituted as the Russian Academy of Sciences on 1991.

Named after Nikolay D. Zelinsky in 1953, the Institute of Organic Chemistry hosts a shared facility center equipped with state of the art spectrometers and electron microscopes in operation the whole year, enabling advanced structural 
6

investigation of molecular systems. Along with academics from Lomonosov Moscow State University, the Institute offers advanced university education which includes experimental classes in its research laboratories. Aiming at fostering valuable contacts with leading international R\&D centers and laboratories engaged in organic chemistry, catalysis and other areas of chemistry, the Institute regularly invites outstanding foreign and Russian scientists for lecturing. Correspondingly, our team at Italy's Research Council is engaged in advancing international education in for the bioeconomy, for which it has developed innovative international courses on nanochemistry, ${ }^{53}$ solar energy $^{54}$ and energy management ${ }^{55}$ looking forward to the foundation of the Institute of bioeconomy.

Finally, we concluded presenting the audience with two relevant though poorly known historical links between Moscow and Palermo. Dmitry Mendeleev considered Stanislao Cannizzaro 'my immediate predecessor'. ${ }^{56}$ Not many Italians are aware that Professor Cannizzaro was a chemist from Palermo, where he carried out the experiments that led him to assess several atomic weights. Even less Italians or Russians nowadays are aware that on October 23, 1845, two powerful steam ships, the Kamchatka and the Bessarabia, entered Palermo's harbor after two days of navigation started in Genua. The ships carried the Czarin Alexandra Fedorovna and several components of Russia's court. The Czarin was going to spend 6 months in Palermo to enjoy the health benefits of the warm city climate. She received the visit of the Czar, Nicholas I, and left in Sicily a great memory.

\section{Acknowledgments}

Professor Valentine P. Ananikov, Laboratory Head at ZIOC, is gratefully acknowledged for the invitation to lecture in Moscow. A special thanks is due to ZIOC Director Mikhail P. Egorov, Laboratory Head Professor Valentine P. Ananikov and Professor Irina P. Beletskaya for the unforgettable rendez-vous after the first lecture on June $8^{\text {th }}$. David Avnir, The Hebrew University of Jerusalem, opened our research avenue in sol-gel materials twenty years ago. The first Moscow's lecture is dedicated to Rosaria Ciriminna, Italy's Research Council (Palermo), and Valerica Pandarus, SiliCycle and Laval Université (Québec). Without these two excellent chemists little or nothing of what we have achieved in sol-gel catalysis would have been possible. The second lecture is dedicated to Francesco Meneguzzo, Italy's Research Council, eminent physicist and energy scholar. The contribute of several outstanding colleagues with whom we had the privilege to cooperate advancing catalysis with sol-gel entrapped materials and chemistry for the bioeconomy is acknowledged. Thanks to Serge Kaliaguine, Laval Université; Francois Béland, Genevieve Gingras, and Delphine Desplantier-Giscard, SiliCycle; Laura M. Ilharco and Alexandra A. Fidalgo, Lisboa University; Yi-Jun Xu and Nan Zhang, Fuzhou University; Leonardo Palmisano, Francesco Parrino, Vittorio Loddo, and Giuseppe Avellone, University of Palermo; Francesco Meneguzzo and Lorenzo Albanese, Italy's Research Council; Michele Rossi and Cristina Della Pina, University of Milano; Joel Moreau and Michel Wong Chi Man, ENCSM Montpellier; Sandro Campestrini, University of Padua, and Massimo Carraro, now at the University of Sassari; Giovanni Palmisano and Gabriele Scandura, Masdar Institute of Science and Technology; former PhD students and post-doc graduates Piera Demma Carà, Riccardo Delisi, Marzia Sciortino and Nino Scurria; Gadi Rothenberg and N. R. Shiju, University of Amsterdam; Sebastián Bonilla Vásquez, University of Panama; Franck Dumeignil, Benjamin Katryniok, Sébastien Paul,
Université Lille; Giancarlo Cravotto and Diego Carnaroglio, University of Torino; Alfredo Tamburino, Legambiente; Carmelo Danzì, University of Catania. I am indebted to Dr Yael Albo, Ariel University, for useful discussion and for sharing information on sol-gel entrapped gold catalysts.

\section{References and notes}

1. R. Ciriminna, E. Falletta, C. Della Pina, J. H. Teles, M. Pagliaro, Angew. Chem. Int. Ed. 2016, 55, 14210-14217.

2. R. Ciriminna, L. M. Ilharco, V. Pandarus, A. Fidalgo, F. Béland, M. Pagliaro, Nanoscale 2014, 6, 6293-6300.

3. D. Avnir, Acc. Chem. Res. 1995, 28, 328-334.

4. M. Pagliaro, V. Pandarus, F. Béland, R. Ciriminna, G. Palmisano, P. Demma Carà, Catal. Sci. Technol. 2011, 1, 736-739.

5. V. Pandarus, R. Ciriminna, F. Béland, M. Pagliaro, Adv. Synth. Catal. 2011, 353, 1306-1316.

6. R. Ciriminna, V. Pandarus, G. Gingras, F. Béland, M. Pagliaro, ACS Sustainable Chem. Eng. 2013, 1, 249-253.

7. V. Pandarus, R. Ciriminna, F. Béland, M. Pagliaro, Catal. Sci. Technol. 2011, 1, 1616-1623.

8. R. Ciriminna, V. Pandarus, F. Béland, M. Pagliaro, Catal. Sci. Technol. 2016, 6, 4678-4685.

9. V. Pandarus, G. Gingras, F. Béland, R. Ciriminna, M. Pagliaro,, Org. Process Res. Dev. 2012, 16, 1307-1311.

10. I. L. Simakova, O. A. Simakova, A. V. Romanenko, D. Yu. Murzin, Ind. Eng. Chem. Res. 2008, 47, 7219-7225.

11. V. Pandarus, R. Ciriminna, S. Kaliaguine, F. Béland, M. Pagliaro, Solvent-Free Hydrogenation of Squalene over SiliaCat $\operatorname{Pd}(0)$, submitted (2017).

12. R. Ciriminna, G. Scandura, V. Pandarus, R. Delisi, A. Scurria, F. Béland, G. Palmisano, M. Pagliaro, ChemCatChem 2017, 9, 1322 1328.

13. R. Ciriminna, A. Fidalgo, V. Pandarus, F. Béland, L. M. Ilharco, M. Pagliaro, Chem CatChem 2015, 7, 254-260.

14. J. Adhikary, M. Meistelman, A. Burg, D. Shamir, D. Meyerstein, Y. Albo, Eur. J. Inorg. Chem. 2017, 2017, 1510-1515.

15. M. Meistelman, J. Adhikary, A. Burg, D. Shamir, G. Gershinsky, D. Meyerstein, Y. Albo, $\mathrm{Ag}^{0}$ and $\mathrm{Au}^{0}$ Nanoparticles Encapsulated in Sol-Gel Matrices as Catalysts in Reductive De-halogenation Reactions, Chim. Oggi Chem. Tod. 2017, 35 (5), xx.

16. O. L. Lebedev, S. N. Kazarnowsky, Treatises on Chemistry and Chemical Technology, Gorki, 1959, 3, 649 (in Russian).

17. R. Ciriminna, M. Pagliaro, Org. Process Res. Dev. 2010, 14, $245-$ 251.

18. A. Michaud, G. Gingras, M. Morin, F. Béland, R. Ciriminna, D. Avnir, M. Pagliaro, Org. Process Res. Dev. 2007, 11, 766-768.

19. V. Pandarus, R. Ciriminna, F. Béland, G. Gingras, M. Drobot, O. Jina, M. Pagliaro, Tetrahedron Lett. 2013, 54, 1129-1132.

20. M. Pagliaro, R. Ciriminna, Tetrahedron Lett. 2001, 42, 45114514.

21. S. Campestrini, M. Carraro, R. Ciriminna, M. Pagliaro, U. Tonellato, Tetrahedron Lett. 2004, 45, 7283-7286.

22. R. Ciriminna, S. Campestrini, M. Pagliaro, Org. Biomol. Chem. 2006, 4, 2637-2641.

23. M. Lemay, V. Pandarus, M. Simard, O. Marion, L. Tremblay, F. Béland, Top. Catal. 2010, 53, 1059-1062.

24. V. Pandarus, D. Desplantier-Giscard, G. Gingras, F. Béland, R. Ciriminna, M. Pagliaro, Org. Process Res. Dev. 2013, 17, 14921497.

25. A. D. Martin, A. R. Siamaki, K. Belecki, B. F. Gupton, J. Flow Chem. 2015, 5, 145-147.

26. R. Greco, W. Goessler, D. Cantillo, C. O. Kappe, ACS Catal. 2015, 5, 1303-1312.

27. J. De M. Muñoz, J. Alcázar, A. de la Hoz and A. Díaz-Ortiz, Adv. Synth. Catal. 2012, 354, 3456-3460.

28. V. P. Ananikov, I. P. Beletskaya Organometallics 2012, 31, 1595 1604.

29. V. Pandarus, G. Gingras, F. Béland, R. Ciriminna, M. Pagliaro, Org. Process Res. Dev. 2011, 16, 117-122.

30. Y. Zhang, R. Ciriminna, G. Palmisano, Y.-J. Xu, M. Pagliaro, RSC Adv. 2014, 4, 18341-18346

31. R. Ciriminna, R. Delisi, F. Parrino, L. Palmisano, M. Pagliaro, Chem. Commun. DOI: 10.1039/C7CC04242F.

32. F. Meneguzzo, R. Ciriminna, L.Albanese, M. Pagliaro, arXiv:1610.07298 [physics.soc-ph]

33. Y.-H. P. Zhang, Energy Sci. Engineer. 2013, 1, 27-41. 
34. Quoted in C. L. Stanitski, L. P. Eubanks, C. H. Middlecamp, N. J. Pienta, Chemistry in Context, $4^{\text {th }}$ ed.; McGraw Hill, Boston: 2003; p 186.

35. F. Meneguzzo, R. Ciriminna, L. Albanese, M.Pagliaro, Energy Sci. Engineer. 2015, 3, 499-509.

36. Government of India, Ministry of New and Renewable Energy, "Historic low Tariff of Rs. 2.44 per unit discovered in Bhadla Phase-III Solar Park in auction by SECI", 12 May 2017.

37. I. Johnston, India cancels plans for huge coal power stations as solar energy prices hit record low, The Independent, 23 May 2017.

38. S. Göß, Development of negative power prices in Germany, blog.energybrainpool.com, 19 January 2017.

39. J. G. Wang, J. Yang, The Power of Batteries: The Story of BYD, In Who Gets Funds from China's Capital Market?, J. G. Wang, J. Yang (Ed.s), Springer, New York: 2013.

40. Hevel Solar, see at the URL: http://en.rusnano.com/portfolio/companies/hevel

41. R. Ciriminna, N. Chavarría-Hernández, A. Rodríguez Hernández, M. Pagliaro, Biofuels, Bioprod. Biorefin. 2015, 9, 368-377.

42. A. Fidalgo, R. Ciriminna, D. Carnaroglio, G. Cravotto, G. Grillo, A. Tamburino, L. M. Ilharco, M. Pagliaro, ACS Sustainable Chem. Eng. 2016, 4, 2243-2251.

43. R. Ciriminna, A. Fidalgo, R. Delisi, D. Carnaroglio, G. Cravotto, A. Tamburino, L. M. Ilharco, M. Pagliaro, ACS Sustainable Chem. Eng. 2017, 5, 5578-5587

44. R. Ciriminna, A. Fidalgo, F. Meneguzzo, L. M. Ilharco, M. Pagliaro, Eur. J. Lipid Sci. Technol. 2016, 118, 503-511.

45. R. Ciriminna, F. Meneguzzo, R. Delisi, M. Pagliaro, ChemistrySelect 2017, 2, 1360-1365.

46. J. del Pilar Ramírez-Anaya, C. Samaniego-Sánchez, Ma. C. Castañeda-Saucedo, M. Villalón-Mir, H. López-García de la Serrana, Food Chem. 2015, 188, 430-438

47. R. Delisi, R. Ciriminna, S. Arvati, F. Meneguzzo, M. Pagliaro, Olive Biophenol Integral Extraction at a Two-Phase Olive Mill,
Preprints 2017, 2017050011, DOI: 10.20944/preprints201705.0011.v1.

48. A. I. Zaytseva, Composition and quality of marine Omega-3 supplements on the Russian and Norwegian markets: $a$ comparative study, Master thesis in International Fisheries Management, The Arctic University of Norway, Faculty of Biosciences, Fisheries and Economics (2014).

49. R. Ciriminna, F. Meneguzzo, R. Delisi, M. Pagliaro, Sustain. Chem. Pharm. 2017, 5, 54-59.

50. Future Market Insights, Essential Fatty Acids Market: Omega-3 Fatty Acid Product Type Segment Likely to Hold Maximum Revenue Share Throughout the Forecast Period: Global Industry Analysis and Opportunity Assessment, 2017-2027, May 2017.

51. L. Albanese, R. Ciriminna, F. Meneguzzo, M. Pagliaro, J. Clean. Prod. 2017, 142, 1457-1470.

52. L. Albanese, R. Ciriminna, F. Meneguzzo, M. Pagliaro, LWT Food Sci. Technol. 2017, 82, 342-353.

53. M. Pagliaro, Chem. Eur. J. 2015, 21, 11931-11936.

54. R. Ciriminna, F. Meneguzzo, M. Pecoraino, M. Pagliaro, Renew. Sustain. Energy Rev. 2016, 63, 13-18.

55. R. Ciriminna, M. Pecoraino, F. Meneguzzo, M. Pagliaro, Energy Res. Soc. Sci. 2016, 21, 44-48.

56. Quoted in H. Hartley, Studies in the History of Chemistry, Clarendon Press, Oxford: 1971; p. 85.

\section{Supplementary Material}

Video and photogallery can be accessed online at: https://goo.gl/i8dhs7. 